\title{
MLM DALAM PERSPEKTIF ULAMA' FIQIH DAN HADIS
}

\author{
Khoirurroji'in \\ IAI Agus Salim Metro
}

\begin{abstract}
Multi Level Marketing (MLM) better known as MLM is, "A direct sales system, where goods are marketed by consumers directly from producers. Consumers who simultaneously market goods receive bonus rewards. These bonuses are taken from the profits of each buyer introduced by first buyer based on regulated provisions "365. Because it is believed to be able to provide substantial profits to companies, today, various types of goods are widely marketed using MLM marketing patterns, jewelry. computer programs, supplement drinks, cosmetics, Islamic tapes and others.

Transactions with this MLM system have penetrated the middle of humans and have a lot to color the atmosphere of the community market. So as a Muslim businessman, it is obligatory to know the legal transactions with this MLM system before struggling in it and the scholars have disagreed about the law.

That a Muslim trader should know the Shari'a laws regarding the rules of trading or transactions and know the forms of buying and selling that are prohibited in religion. The lack of knowledge about this will cause a person to fall into error and sin. As we have witnessed the spread of usury practices, consuming human property in a vanity way, damaging market prices and so on from forms of damage that harm society, even harming the state.
\end{abstract}

Keyword: Multi Level Marketing, MLM) Ulama Fiqih, Ulama Hadis, Perspektif

\section{Pendahuluan}

Bagi masyarakat Indonesia istilah Multi Level Marketing yang disingkat (MLM). Sistem perdagangan ini dipraktekkan oleh berbagai perusahaan, baik yang berskala lokal, nasional, terutama para pelaku bisnis, istilah Multi Level Marketing (MLM). tidak asing lagi karena banyak n-perusahaan yang memasarkan produknya melalui sistem MLM. Sampai sekarang sudah ada sekitar 200 perusahaan yang mengatasnamakan dirinya menggunakan sistem MLM. Sistem pemasaran melalui MLM menjadi menarik karena melibatkan masyarakat konsumen dalam kegiatan pemasaran produk, dan konsumen diiming-imingi, selain dapat menikmati manfaat produk, juga bisa memperoleh insentif atau hadiah-hadiah yang ditawarkan produsen, seperti haji dan umrah, perlindungan asuransi, tabungan hari tua dan lain sebagainya. Bagi produsen sendiri, melalui sistem MLM dapat melakukan efisiensi biaya distribusi produk sminimal mungkin atau bahkan bisa di tekan sampai ketitik nol. MLM juga menghilangkan biaya promosi karena distribusi dan promosi ditangani langsung oleh distributor dengan sistem berjenjang (pelevelan).

Model MLM banyak sekali macamnya dan setiap perusahaan memiliki spesifikasi tersendiri. Sejak masuk ke Indonesia pada sekitar tahun 80-an, jaringan bisnis penjualan langsung (direct selling) MLM terus marak dan bertambah subur laksana tumbuhnya jamur di musim hujan setelah badai krisis moneter dan ekonomi 1998. Pelaku bisnis yang terjun di dunia MLM memanfaatkan situasi krisis untuk menawarakan solusi kerja part time tapi "dapat" mendatangkan penghasilan besar. Beberapa perusahaan yang cukup popular di masyarakat di antaranya CNI, Amway, Avon, Tupperware, Sun Chlorella, DXN, Propolis Gold, Kamyabi-Net, Persada Network, Tianshi dan Gee Cosmos.

Pada awal tahun 2000-an, berkat promosi yang sangat gencar, masyarakat Indonesia terkena bujuk rayu, terpedaya dan mengalami "demam" MLM, karena sekilas memang MLM "menjanjikan" pendapatan yang 


\section{AT TAAJIR}

Vol. 1, No. 1, (2019)

ISSN : 2685-435X

Juli - Desember

E-ISSN :

fantastis, namun belakangan terlihat mengalami kelesuan. Hanya saja akhir-akhir ini muncul geliatnya dengan menggunakan modus memberi label "syari'ah", seiring dengan semakin menggeliatnya sistem transaksi/keuangan syariah. Permasalahannya kemudian adalah, benarkah bawa perusahaan yang mengusung sistem MLM dengan belabel syari'ah itu benar -benar telah memenuhi standard syari'ah dan apa sejatinya parameter kesyariahan MLM tersebut ? Inilah yang akan didiskusikan pada makalahyang sederhana ini.

\section{Konsep Multi Level Marketing (MLM)}

MLM adalah singkatan dari Multi Level Marketing (Pemasaran Multi Tingkat), yaitu sistem pemasaran melalui jaringan distribusi yang dibangun secara berjenjang dengan memposisikan pelanggan perusahaan sekaligus sebagai tenaga pemasaran.

MLM adalah sistem penjualan yang memanfaatkan konsumen sebagai tenaga penyalur secara langsung. Sistem penjualan ini menggunakan beberapa level (tingkatan) di dalam pemasaran barang dagangannya. Jadi, Multi Level Marketing adalah suatu konsep penyaluran barang (produk dan jasa tertentu) yang memberi kesempatan kepada para konsumen untuk turut terlibat sebagai penjual dan memperoleh keuntungan di dalam garis kemitraannya. MLM disebut juga Network Marketing, Multi Generation Marketing dan Uni Level Marketing. Namun dari semua istilah itu, yang paling populer adalah istilah Multi Level Marketing.

Dengan kata lain, MLM sebuah metode pemasaran barang dan atau jasa dari sistem penjualan langsung melalui program pemasaran berbentuk lebih dari satu tingkat, dimana mitra usaha mendapatkan komisi penjualan dan bonus penjualan dari hasil penjualan barang dan jasa yang dilakukannya sendiri dan anggota jaringan didalam kelompoknya.

Sistem ini memiliki ciri-ciri kusus yang membedakannya dengan sistem pemasan lain, diantara cirri-ciri kusus tersebut adalah: terdapatnya banyak jenjang atau level, melakukan perekrutan anggota baru, penjualan produk, terdapat sistem pelatihan, serta adanya sistem komisi atau bonus untuk tiap jenjangnya. ${ }^{1}$

Suatu yang khas dari MLM adalah adanya sistem penjenjangan atau tingkatan untuk setiap distribrutor yang bergabung, sesuai dengan prestasinya. Seperti halnya meniti karier dalam bisnis ini dari tingkat yang paling bawah. Menjalaninya langkah demi langkah, hingga ia berhasil naik peringkat dan terus naik peringkat.

Setiap distributor yang mampu merekrut beberapa down line, secara otomatis peringkatnya akan naik. Jika ia mampu membina down line-nya untuk melakukan hal serupa peringkatnya akan terus menanjak sesuai dengan bertambanya jaringan. Inilah yang dimaksud dengan pertumbuhan eksponensial. ${ }^{2}$

Pada intinya, konsep bisnis MLM adalah berusaha memperpendek jalur distribusi yang ada pada sistem penjualan konvensional dengan cara memperpendek jarak antara produsen dan konsumen. Dengan memperpendek jarak ini memungkinkan biaya distribusi yang minim atau bahkan bisa ditekan sampai ketitik paling rendah. MLM juga menghilangkan biaya promosi karena distribusi dan promosi ditangani langsung oleh distributor dengan sistem berjenjang (pelevelan). Sebenarnya MLM bukanlah formula ajaib untuk bisa mendatangkan uang dengan cepat dan mudah. MLM hanyalah suatu metode untuk memasarkan suatu produk

\footnotetext{
${ }^{1}$ Muhammad Syafi'I Antonio. MENGENAL MLM SYARI'AH Dari Halal-Haram, Kiat Berwirausaha, Sampai dengan Pengelolanya. (Tangerang:Qultum Media,2005)hal.17

${ }^{2}$ Ibid, hal.50
} 


\section{AT TAAJIR}

Vol. 1, No. 1, (2019)

ISSN : 2685-435X

Juli - Desember

E-ISSN :

yang berbeda-beda dengan cara konvensional. MLM adalah suatu metode alternative yang berhubungan dengan pemasaran dan distribusi. ${ }^{3}$

Perhatian dalam bisnis ini adalah menentukan cara terbaik untuk menjual produk dari suatu perusahaan melalui inovasi dibidang pemasaran dan distribusi. Artinya. MLM hanya berkaitan denngan cara menjual suatu produk dengan lebih efisien dvan efektif kepada pasar, dan tidak berhubungan dengan penciptaan kekayaan.

Bisnis MLM dalam kajian fiqh kontemporer dapat ditinjau dari dua aspek produk barang atau jasa yang dijual dan cara ataupun sistem penjualan (selling/marketing). Mengenai produk yang dijual, apakah halal atau haram bergantung kandungannya, apakah terdapat sesuatu yang diharamkan Allah menurut kesepakatan (ijma') ulama atau tidak, begitu juga jasa yang dijual. Unsur babi, khamar, bangkai, darah, perzinaan, kemaksiatan, perjudian contohnya. Lebih mudahnya sebagian produk barang dapat dirujuk pada sertifikasi halaldari LP-POM MUI, meskipun produk yang belum disertifikasi halal juga belum tentu haram bergantung pada kandungannya. ${ }^{4}$

Perusahaan yang menjalankan bisnisnya dengan MLM tidak hanya menjalankan penjualan produk barang, tetapi juga produksi jasa, yaitu jasa marketing yang berlevel-level(bertingkat-tingkat) dengan imbalan berupa marketing fee, bonus, dan sebagaimana bergantung level, prestasi penjualan, dan status keanggotaan distributor. Jasa perantara penjualan ini (makelar) dalam terminology fiqh disebut "samsarah/simsar" ialah perantara perdagangan (orang yang menjualkan barang atau mencarikan pembeli) atau perantara antara penjual dan pembeli untuk mempermudah jual beli 5

Pekerjaan samsarah/simsar berupa makelar, distributor, agen, dan sebagainya dalam figh islam adalah termasuk akad ijarah yaitu suatu transaksi memanfaatkan jasa orang dengan imbalan. Pada dasarnya, para ulama seperti Ibnu Abbas, Imam Bukhari, Ibvnu Sirin, Atha, Ibrahim, memandang boleh saja ini. Namun untuk sahnya pekerjaan makelar ini harus memenuhi beberapa syarat disamping persyaratan tadi antara lain :

a. Perjanjian diantara kedua belah pihak jelas.

b. Obyek akad bisa diketahui manfaatnya secara nyata dan dapat diserahkan

c. Obyek akad bukan hal-hal yang maksiat atau haram.

\section{SISTEM PEMASARAN MODEL MLM}

Pakar marketing ternama Don Failla, membagi marketing menjadi tiga macam. Pertama; retail (eceran), Kedua; direct selling (penjualan langsung ke konsumen); Ketiga, multi level marketing, yakni pemasaran berjenjang melalui jaringan distribusi yang dibangun dengan memposisikan pelanggan sekaligus sebagai tenaga pemasaran). Multi level marketing ( MLM) secara harfiah berarti pemasaran yang dilakukan melalui banyak level atau tingkatan, yang biasanya dikenal dengan istilah up line (tingkat atas) dan down line (tingkat bawah). Up line dan down line umumnya mencerminkan hubungan pada dua level yang berbeda atas dan bawah, maka seseorang disebut up line jika mempunyai down line, baik satu maupun lebih. Bisnis yang menggunakan multilevel marketing ini memang digerakkan dengan jaringan,

\footnotetext{
${ }^{3}$ Ibid, hal.20

${ }_{5}^{4}$ Setiawan Budi Utomo.FIQH ACTUAL (Jakarta : Gema Insani Pers.2003).hal.102-103

5 Ibid, 103
} 


\section{AT TAAJIRR}

Vol. 1, No. 1, (2019)

Juli - Desember

ISSN : 2685-435X

E-ISSN :

yang terdiri dari up line dan down line. Meski masing-masing perusahaan dan pebisnisnya menyebut dengan istilah yang berbeda-beda. Demikian juga dengan bentuk jaringannya, antara satu perusahaan dengan yang lain, mempunyai aturan dan mekanisme yang berbeda; ada yang vertikal dan ada pula yang horisontal.

Berikut adalah contoh model jaringan MLM :

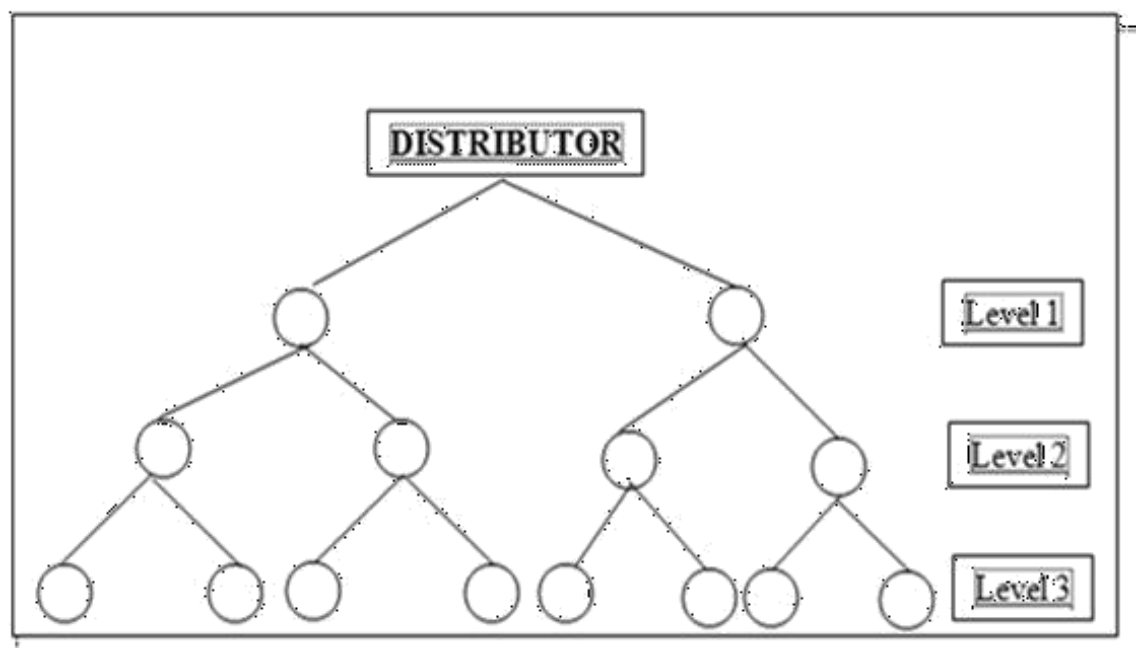

\section{Pendapat ulamak tentang hukum MLM}

Pendapat pertama: MLM hukumnya mubah (boleh).

Ini merupakan pendapat Lembaga fatwa Al Azhar, Mesir. Karena dianggap sama dengan samsarah (perantara antara penjual dan pembeli /calo). Berikut teks soal-jawab tentang perusahaan "BIZNAS salah satu perusahaan program komputer di timur tengah yang berdiri pada tahun 2001, berpusat di Kesultanan Oman, yang menggunakan sistem MLM dalam memasarkan produknya. Pada tahun 2008 perusahaan ini telah memiliki 110.000 anggota yang tesebar di 50 negara Soal: Sebuah perusahaan yang berpusat di Oman baru membuka cabang di Mesir, bernama "BIZNAS". Perusahaan ini menjual program panduan belajar komputer, mencakup program panduan menggunakan komputer, internet, panduan servis komputer dan program-program pembelajaran lainnya, selalu di update melalui situs resmi perusahaan, dijual seharga $\$ 90$. Pada saat pembelian produk, pembeli memperoleh program atau dapat menjualnya kembali. Selain itu dia mendapat kesempatan untuk bergabung dalam jaringan untuk meraih keuntungan dengan

cara memasarkan barang kepada orang-orang terdekat. Karena dia telah berusaha meyakinkan pihak lain untuk membeli produk dan juga telah membeli produk dan juga dia melatih orang-orang yang membeli produk melaluinya untuk menggunakan produk dan memasarkan ke pihak lain. Pada saat ia mendapatkan 9 orang pembeli produk baik langsung maupun tidak, dengan syarat 2 orang pembeli produk langsung melaluinya maka perusahaan akan memberikan bonus sebagai motivasi agar terus memasarkan produk dan dia akan terus menerima bonus selama orang membeli produk melalui jaringannya.

Fatwa ini ditanggapi oleh banyak para peneliti ekonomi Islam. Menurut Dr. Husein Syahrani dalam desertasinya yang diajukan ke Fakultas Syariah, Universitas Islam A1 Imam Saud, Riyadh, Arab Saudi yang berjudul "At Taswiq At Tijary wa ahkamuhu fil Fiqh Al Islami" bahwa fatwa ini tidak berarti membolehkan sistem MLM secara mutlak, disebabkan beberapa hal: 


\section{AT TAAJIR}

Vol. 1, No. 1, (2019)

ISSN : 2685-435X

Juli - Desember

E-ISSN :

a. Fatwa tersebut berdasarkan deskripsi yang disampaikan . tanpa mengkaji ulang secara langsung sistem yang digunakan perusahaan yang bersangkutan, sebagaimana dijelaskan pada pembukaan fatwa. Padahal kalau permasalahan menjelaskan hal-hal yang dapat mempengaruhi hukum MLM kemungkinan fatwanya berbunyi lain, seperti bahwa pembelian produk merupakan syarat untuk dapat memasarkan barang dan meraih bonus, lalu tujuan utama orang membeli produk untuk ikut MLM adalah meraih bonus yang dijanjikan, perbandingan bonus yang dijanjikan sangat jauh dibandingkan dengan harga produk dan usahanya memasarkan barang.

Misalnya, BIZNAS menjanjikan bonus sebanyak lima puluh ribu Dollar Amerika di akhir tahun, padahal harga produk tidak lebih dari $\$ 99$,dengan perbandingan $0.3 \%$ harga produk dan bonus $99,7 \%$ ini pasti membuat setiap orang yang membeli produk serta ikut jaringan bertujuanl mendapatkan bonus dan bukan menginginkan produk. karena ternyata program-program yang dijual oleh BIZNAS dapat diperoleh dari beberapa situs di internet secara gratis, serta usahanya untuk meraih bonus hanya cukup memasarkan produk kepada dua orang di bawah tingkatan, kemudian dua orang di bawah mencari dua orang lagi dan seterusnya.

Juga tidak dijelaskan dalam pertanyaan bahwa untuk mendapatkan bonus disyaratkan bahwa 9 penjualan harus berasal dari downline jalur kiri-kanan seimbang, 5 penjualan dari downline kanan dan 4 dari kiri atau 63 , jika seluruh penjualan hanya dari satu jalur saja maka bonus gagal diperoleh sekalipun ribuan penjualan.

b. Fatwa ini tidak membolehkan secara mutlak akan tetapi berkait, yaitu tidak terdapat penipuan, kecurangan dan kezaliman dalam memasarkan produk.

Persyaratan ini tidak terpenuhi dalam praktik MLM, karena kenyataannya, pada saat memasarkan produk dan sekaligus merekrut downline selalu dipenuhi kecurangan, penipuan dan kezaliman. Di mana upline menjanjikan bonus yang sangat besar kepada calon pembeli, padahal yang mendapatkan bonus itu hanya $6 \%$ saja dari seluruh anggota, ini namanya spekulasi tingkat tinggi (judi), dengan janji itu pembeli bersedia membeli produk yang harganya jauh lebih mahal dibandingkan harga sebenarnya, bahkan produk BIZNAS dapat diperoleh secara gratis, ini adalah kezaliman dan kecurangan dalam penjualan produk.

c. Fatwa yang menganggap MLM sama dengan samsarah (Calo) tidaklah tepat, karena terdapat perbedaan yang me"dasar antara MLM dan samsarah ${ }^{6}$

\begin{tabular}{|c|c|}
\hline Samsaroh ( calo) & MLM \\
\hline $\begin{array}{l}\text { Untuk menjadi perantara tidak disyaratkan harus } \\
\text { membeli produk terlebih dahulu. }\end{array}$ & $\begin{array}{l}\text { Untuk menjadi anggota MLM di haruskan } \\
\text { membeli produk. ini termasuk dalam larangan } \\
\text { Nabi Muhammad shallallahu 'alaihi wa sallam, } \\
\text { dua jual-beli dalam satu jual beli, yaitu: untuk bisa } \\
\text { memasarkan barang dia harus melakukan (1 } \\
\text { akad ijarah) dan dia harus membeli barang (1 } \\
\text { akad ba'i) }\end{array}$ \\
\hline
\end{tabular}

\footnotetext{
${ }^{6}$ Dr. Husein Syahrani, At Taswiq At Tijary wa ahkamuhu fil Fiqh AI Islami,h.525-528
} 


\section{AT TAAJIR}

Vol. 1, No. 1, (2019)

ISSN : 2685-435X

Juli - Desember

E-ISSN :

\begin{tabular}{|l|l|}
\hline $\begin{array}{l}\text { perantara (agen) mendapat imbalan dari setiap } \\
\text { barang yang dijualnya kepada Siapapun. }\end{array}$ & $\begin{array}{l}\text { Dalam MLM, seseorang mendapat bonus jika } \\
\text { menjual barang kepada dua orang kemudian dua } \\
\text { orang itu menjual barang lagi kepada dua orang } \\
\text { dan begitu seterusnya. jika persyaratan ini tidak } \\
\text { terpenuhi, bonus tidak akan didapat. }\end{array}$ \\
\hline $\begin{array}{l}\text { Upah yang di trima oleh perantara jelas } \\
\text { jumlahnya baik dengan cara persentase harga } \\
\text { barang ataupun dengan cara penetapan }\end{array}$ & $\begin{array}{l}\text { Upah (bonus) Yang akan diterima oleh penjual } \\
\text { produk MLM tidak jelas dan ini termasuk gharar }\end{array}$ \\
\hline
\end{tabular}

Pendapat kedua : MLM hokum nya tidak boleh ( haram)

Ini merupakan penaapat mayoritas para ulama kontemporer, juga fatwa dewan ulama kerajaan Arab

Saudi, keputusan Lembaga fikih Islam di Sudan dan fatwa pusat kajian dan penelitian Imam Alf Albani, Yordania.

Menurut Dr. Sami As Suwaylim ( Direktur Pengembangan Keuangan Islam di Islamic Development Bank, jeddah dan bekas anggota dewan syariah bank Al Rajhi, Riyadh) dalam sebuah penelitiannya mengatakan bahwa MLM adalah perpanjangan dari Pyramid scheme/Letter Chain (pengiriman uang secara berantai) yang berasal dari Amerika. ' Tatkala pemerintah setempat melarang praktik ini karena dianggap sebagai penipuan maka sistem ini dikembangkan dengan memasukkan unsur barang/produk agar mendapat legalitas dari pemerintah.

Sangat ironis sekali, jika saja negara yang menganut sistem liberal dalarn ekonominya -menghalalkan riba dan judi telah melarang praktik ini kenapa juga ulama Islam masih ragu-ragu meniatuhkan hukum praktik ini. Ide asas kerja MLM adalah sebagai berikut:

Menyerahkan uang sebanyak $\$ 100$ kepada Sebuah perusahaan dengan harapan mendapatkan bonus yang jauh lebih besar dari nominal uang yang dibayar ke perusahaan tersebut. Agar A mendapat bonus, dia harus mencari dua orang yang mau menyerahkan uang $\$ 100$ kepada sebuah perusahaan itu untuk menutupi uang $A \$ 100$ dan agar dapat bonus serta sisanya merupakan laba bagi perusahaan pengelola. Kemudian B dan $C$ yang telah membayar masing- masing $\$ 100$ ke perusahaan melalui perantara $A$ agar Uangnya kembali dan mendapat bonus masing-masing harus mencari dua orang yang mau menyerahkan uang $\$ 100$. Maka jumlah orang pada level ini empat orang, begitulah seterusnya hingga skema piramida ini membesar, di mana jumlah peserta di tingkat bawah lebih banyak daripada iumlah tingkat atas. Yang pasti, semakin lama berjalan maka semakin susah untuk merekrut orang baru yang mau menyerahkan uangnya kepada perusahaan pengelola dan pada suatu saat sampai pada kondisi stagnan, tidak bergerak. Maka dapat dipastikan orang-orang yang berada pada tingkat akhir mengalami kerugian dan jumlah anggota pada tingkat ini adalah peserta terbanyak. ini adalah sebuah penipuan, yaitu: memberikan keuntungan untuk sedikit orang dan merugikan orang banyak. Dalam hitungan matematika persentase anggota yang mengalami kerugian mencapai 94\% sedangkan anggota level atas yang meraih keuntungan hanyalah $6 \%$ saia. ini sangat jelas merupakan penipuan. 


\section{AT TAAJIR}

Vol. 1, No. 1, (2019)

Juli - Desember

ISSN : 2685-435X

E-ISSN :

Oleh karena itu, pemerintah Amerika telah melarang praktik Pyramid Scheme. Namun agar sistem ini dapat diakui oleh pemerintah maka pihak pengelola memasukkan produk sebagai kedok. Dan namanya diubah menjadi Multi Level Marketing, Direct Selling dan lain-lain.

Hukum pyramid scheme jelas haram, karena mengandung unsur riba ba'i, yaitu: menukar uang sejenis dengan cara tidak tunai dan tidak sama nominalnya, juga mengandung unsur gharar, yaitu: saat seseorang bergabung dengan sebuah jaringan Pyramid Scheme dia tidak tahu apakah uang yang telah dibayarkannva akan kembali

Ditambah bonus, karena dia berada di tingkat atas atau uang dan bonusnya hilang, karena statusnya berada pada tingkat bawah.

Bila hukum ini telah disepakati, maka selanjutnya yang perlu dikaji apakah penyertaan sebuah barang/produk ke dalam sistem ini dapat mengubah hukum MLM menjadi halal atau tidak?

Seseorang yang bergabung dengan MLM ada 3 macam:

a. Seseorang yang murni bertujuan untuk menjadi perantara antara produsen dan konsumen (agen) dengan sistem MLM.

Perantara ini tidak dapat menjualkan produk sebagaimana layaknya perantara dalam sistem marketing biasa, yaitu barang diambil terlebih dahulu berdasarkan kepercayaan kemudian ia mendapat upah sekian persen dari hasil penjualan. Akan tetapi ia diharuskan terlebih dahulu membeli salah satu produk tersebut. Proses ini jelas dilarang dalam Islam karena terdapat dua akad dalam satu akad. Dan tujuan di balik persyaratan perantara harus membeli salah satu produk terlebih dahulu perlu dicermati. Karena persyaratan ini merupakan indikasi kuat bahwa produk hanya sebatas kedok untuk melegalkan Pyramid Scheme. Karena bila ia hanya sebatas perantara tanpa membeli produk maka mata rantai Pyramid Scheme akan terputus. ' Dengan demikian pengelola jaringan akan mengalami kerugian, karena bonus yang diberikan jauh lebih besar dari pada hasil penjualan barang.

b. Seseorang yang bertujuan membeli produk saja tanpa ambil peduli dengan bonus yang dijanjikan perusahaan MLM karena ia merasa cocok dengan produknya.

Maka konsumen ini sesungguhnya telah tertipu. Karena harga jual yang telah ditetapkan oleh perusahaan lebih dari $60 \%$ dianggarkan untuk pemberian bonus, hal ini disepakati oleh seluruh perusahaan MLM. Maka pembeli yang hanya membeli barang saja dia telah tertipu karena harus membayar $60 \%$ dari harga barang untuk bonus orang-orang dalam jaringan, padahal ia membeli produk langsung dari tangan pertama. Berbeda dengan harga barang yang sampai ke tangannya melalui sistem marketing biasa sekalipun termasuk biaya agen dan iklan akan tetapi jika ia memotong jalur perantara dia dapat memperoleh potongan harga. Persentase lebih dari 60 untuk bonus dan kurang dari 40 untuk biaya produksi barang jelas bahwa status barang hanyaa sebagai kedok untuk melegalkan Pyramid Scheme, dimana : yang diinginkan adalah uang dan bukan barang.

c. Seseorang yang ikut bergabung dalam MLM dengan tuhh. bonus Karena bonus yang dijanjikan untuk tahun pertama "ia sangat besar dan jauh dibanding harga barang Yang dipasarkan kepada kedua orang yang sekaligus merupakan downline-nya. Dan tujuan ini merupakan tujuan utama mayoritas orang. 


\section{AT TAAJIR}

Vol. 1, No. 1, (2019)

Juli - Desember

ISSN : 2685-435X

E-ISSN :

orang yang bergabung dalam MLM, yaitu memperoleh bonus puluhan juta rupiah. Dan mereka sama sekali tidak menghiraukan produk yang dijual dan dibelinya. Dalam kasus ini jelas bahwa barang hanyalah sebagai kedok untuk melegalkan Pyramid Scheme.

Dari penjelasan di atas sangat jelas bahwa sistem MLM tidak berbeda hukumnya dengan Pyramid Scheme, sekalipun disertakan barang/produk karena status barang hanyalah sebagai kedok.

Hal ini dicermati oleh Dewan Fatwa kerajaan Arab Saudi» dengan fatwa No. 22935, tanggal: 14-3-1425H, yang berbunyi: tentan hukum MLM seperti; "BIZNAS" dan 'Hlbatullaglrah , inti system pemasarannya: setiap anggota berusaha meyakinkan 2 orang untuk membeli produk, kemudian setiap pembeli tadi berusaha meyakinkan 2 orang lagi untuk membeli. Semakm tiggi tingkatan peserta semakin besar bonus yang dldapatkan. Mencapai ribuan Riyal. .

Sistem ini (MLM) termasuk muamalat yang diharamkan. Karena tujuan orang yang bergabung adalah bonus dan bukan barang. Terkadang bonus mencapai ribuan Riyal sedangkan harga barang hanyalah ratusan riyal. Setiap orang yang berakal bila ditawarkan pilihan barang dan bonus pasti akan memilih bonus.oleh karena itu yang menjadi jargon perusahaan MLM menarik orang untuk membeli produknya adalah besarnya bonus yang dijanjikan, sebagai imbalan harga barang yang tidak seberapa bila dibandingkan dengan bonus yang akan diperoleh. .?

Berdasarkan penjelasan hakikat sistem pemasaran ini maka hukumnya adalah haram sesuai dengan dalil-dalil berikut:

1, sistem MLM mengandung unsur riba fadhl dan nasi'ah.

Setiap anggota menyerahkan uang dalam jumlah kecil untuk mendapatkan uang dalam jumlah yang lebih besar. Ini berarti uang ditukar dengan uang dengan nominal yang tidak sama dan tidak tunai. Inilah riba yang diharamkan berdasarkan teks Alquran dan Hadis, beserta ljma '.

Sedangkan status barang / produk yang dijual perusahaan kepada konsumen hanyalah sebatas kedok, karena barang bukanlah tujuan orang yang ikut dalam jaringan tersebut. .Dengan demikian keberadaan barang tidak mempengaruhi hukum ( menjadi halal).

2.Sistem MLM mengandung unsur gharar (spekulasi) yang diharamkan syariat.

Karena setiap orang yang ikut dalam jaringan ini, ia tidak tahu apakah akan berhasil merekrut anggota (downline) dalam jumlah yang diinginkan atau tidak. Sedangkan jaringan ini sekalipun terus beroperasi, suatu saat pasti akan terhenti, maka pada saat ia bergabung ke dalam jaringan ia tidak tahu, apakah dia berada pada tingkat atas dengan demikian dia akan beruntung. Ataukah dia akan berada pada tingkat bawah dengan demikian dia akan rugi. Dan kenyataannya, sebagian besar anggota jaringan menderita kerugian dan hanya sebagian'kecil saja yang meraih keuntungan.

${ }^{7}$ Perusahaan ini berdiri pada tahun 2003M, berpusat di Riyadh. Produknya CD yang berisi program buku-buku Islam dalam bentuk elektronik. Dipasarkan dengan sistem MLM. 1 keping CD dijual dengan harga SR.500,-. 


\section{AT TAAJIR}

Vol. 1, No. 1, (2019)

ISSN : 2685-435X

Juli - Desember

E-ISSN :

Dengan demikian, persentase terbesar adalah rugi, inilah hakikat gharar. Yaitu keberadaannya antara untung dan rugi, dengan rasio rugi lebih besar.

Dan Nabi shallallahu 'alaihi wa sallam telah melarang Gharar, sebagaimana diriwayatkan oleh Muslim dalam kitab Shahih.

3. Sistem MLM mengandung unsur memakan harta manusia dengan cara yang batil.

Karena yang mendapat keuntungan dari sistem ini hanyalah perusahaan MLM dan sejumlah kecil anggota dalam rangka mengelabui orang-orang untuk ikut bergabung.

\section{Penjelasan Hadis Tentang Larangan Jual Beli Dengan Sistem MLM}

"Nabi shallallaahu 'alaihi wasallam telah melarang dua pembelian dalam satu pembelian."( HR Tirmidzi, Nasai dan Ahmad. Berkata Imam Tirmidzi : Hadist Abu Hurairah adalah hadist Hasan Shahih dan bisa menjadi pedoman amal menurut para ulama)

a. Di dalam transaksi dengan metode MLM, seorang anggota mempunyai dua kedudukan: Kedudukan pertama, sebagai pembeli produk, karena dia membeli produk secara langsung dari perusahaan atau distributor. Pada setiap pembelian, biasanya dia akan mendapatkan bonus berupa potongan harga.Kedudukan kedua, sebagai makelar, karena selain membeli produk tersebut, dia harus berusaha merekrut anggota baru. Setiap perekrutan dia mendapatkan bonus juga.

Kesimpulannya bahwa melakukan dua macam akad dalam satu transaksi yang mengikat satu dengan yang lainnya adalah haram berdasarkan hadist di atas.

b. $\quad$ Di dalam MLM terdapat makelar berantai. Sebenarnya makelar (samsarah) dibolehkan di dalam Islam, yaitu transaksi di mana pihak pertama mendapatkan imbalan atas usahanya memasarkan produk dan pertemukannya dengan pembelinya.

c. Di dalam MLM terdapat unsur perjudian, karena seseorang ketika membeli salah satu produk yang ditawarkan, sebenarnya niatnya bukan karena ingin memanfaatkan atau memakai produk tersebut, tetapi dia membelinya sekedar sebagai sarana untuk mendapatkan point yang nilainya jauh lebih besar dari harga barang tersebut. Sedangkan nilai yang diharapkan tersebut belum tentu ia dapatkan.

d. Di dalam MLM banyak terdapat unsur gharar (spekulatif) atau sesuatu yang tidak ada kejelasan yang diharamkan Syariat, karena anggota yang sudah membeli produk tadi, mengharap keuntungan yang lebih banyak. Tetapi dia sendiri tidak mengetahui apakah berhasil mendapatkan keuntungan tersebut atau malah merugi.

Dan Nabi Muhammad shallallaahu 'alaihi wasallam sendiri melarang setiap transaksi yang mengandung gharar, sebagaimana diriwayatkan oleh Abu Hurairah radhiyallahu 'anhu bahwasanya ia berkata :

"Rasulullah shallallaahu 'alaihi wasallam melarang jual beli dengan cara al-hashah (yaitu: jual beli dengan melempar kerikil) dan cara lain yang mengandung unsur gharar (spekulatif)." (HR. Muslim, no: 2783)

e. Di dalam MLM terdapat hal-hal yang bertentangan dengan kaidah umum jual beli, seperti kaidah : $A I$ Ghunmu bi al Ghurmi, yang artinya bahwa keuntungan itu sesuai dengan tenaga yang dikeluarkan atau resiko yang dihadapinya. Di dalam MLM ada pihak-pihak yang paling dirugikan yaitu mereka yang berada di 


\section{AT TAAJIR}

Vol. 1, No. 1, (2019)

ISSN : 2685-435X

Juli - Desember

E-ISSN :

level-level paling bawah, karena merekalah yang sebenarnya bekerja keras untuk merekrut anggota baru, tetapi keuntungannya yang menikmati adalah orang-orang yang berada pada level atas.

f. Sebagian ulama mengatakan bahwa transaksi dengan sistem MLM mengandung riba riba fadhl, karena anggotanya membayar sejumlah kecil dari hartanya untuk mendapatkan jumlah yang lebih besar darinya, seakan-akan ia menukar uang dengan uang dengan jumlah yang berbeda. Inilah yang disebut dengan riba fadhl (ada selisih nilai). Begitu juga termasuk dalam kategori riba nasi'ah, karena anggotanya mendapatkan uang penggantinya tidak secara cas.

\section{Penutup}

Bisnis MLM merupakan salah satu jenis akad jual beli (al-bai') dengan sistem penjualan langsung (direct seling) atau net work marketing yang memberdayakan distributor independent untuk memasarkan produk langsung secara mandiri. Dalam literatur hukum Islam, selama bisnis MLM tersebut bebas dari unsur-unsur haram, seperti riba, gharar, dzulm dan maisir, maka hukumnya adalah mubah. Sebaliknya, bisnis MLM atau bisnis lain yang mengatasnamakan MLM, seperti money game, yang di dalamnya terdapat unsur gharar, maisir dan dzulm, maka hukumnya adalah haram. Untuk itu, masyarakat muslim hendaknya berhati-hati dan tidak mudah tergiur dengan bisnis MLM karena tidak menutup kemungkinan terjadinya gharar, dzulm, maisir dan ketidakadilan.

\section{Daftar pustaka}

Ahmad Sabiq bin Abdul Latif Abu Yusuf. "Multilevel Marketing". http:///www.alhelaly.com., diakses 17 September 2013.

Djakfar, Muhammad. Etika Bisnis: Menangkap Spirit Ajaran Langit dan Pesan Moral Ajaran Islam. Jakarta: Penebar Plus, 2012.

Djazuli, A. Kaidah-kaidah Fikih: Kaidah-kaidah Hukum Islam dalam Menyelesaikan Masalahmasalah yang Praktis. Jakarta: Kencana, 2006.

Efayanti, Indria Mukti. "Analisis Kelayakan Finansial Bisnis MLM sebagai Alternatif Berwirausaha: Studi Kasus Distributor Amway Indonesia dengan Sistem Network Twentyone". Skripsi, Institut Pertanian Bogor, 2006.

Fauzia, Ika Yunia. "Perilaku Bisnis dalam Jaringan Pemasaran: Studi Kasus Pemberian Kepercayaan dalam Bisnis Multilevel Marketing Shariah (MLMS) pada Herba al-Wahida (HPA) di Surabaya". Disertasi, IAIN Sunan Ampel, Surabaya, 2011.

Kahf, Monzer. 300 Fatwas on Financial Issues. Terj. Nur Cholis. Solo: PT. Aqwam Media Profetika, 2010.

Majah, Ibnu. Sunan Ibnu Majah. Juz. II, Beirut: Dar al-Fikr, 1995.

Rivai, Veithzal. Islamic Marketing: Membangun dan Mengembangkan Bisnis dengan Praktik Marketing Rasulullah SAW. Jakarta: Gramedia Pustaka Utama, 2012.

Sholihati, Ami. "Tinjauan Hukum Islam Tentang Insentif Passive Income pada Multilevel Marketing Syari'ah di PT. K-Link International". Skripsi, IAIN Walisongo Semarang, 2012.

Dr. Husein Syahrani, At Taswiq At Tijary wa ahkamuhu fil Fiqh Al Islami,

Tampubolon, Robert. Sinergi 9 Kekuatan MLM Support System dan Koperasi.Jakarta: Gramedia, 2007 